\title{
Temporal and spatial evolution characteristics of water environment quality in Heze
}

\author{
Qian Gao, Qiang Zhao*, and Xiumei Li \\ School of Water Conservancy and Environment, University of Jinan, Jinan 250022, China
}

\begin{abstract}
The evolution of water environment is relatively complicated. The study of its characteristics is helpful to grasp the general direction of spatial and temporal evolution of water environment in Heze city, and to carry out water resources development and water environment protection more rationally. The comprehensive pollution index method for calculation, and the observed data are handled by Excel. In order to facilitate the analysis of the basin, Arcgis is utilized to map the watershed map. In addition, for the spatial evolution, surfer12 is used to analyze the spatial evolution characteristics the spatial evolution, and to draw the pictures of spatial evolution of chemical oxygen demand and water quality evolution. The study shows that: (1) In Heze, the quality of water environment has been improved year by year from 2006 to 2013. In 2014, the water environment has deteriorated. The content of volatile phenol has increased greatly, and the evolution trend of COD is close to the trend of the comprehensive pollution index. (2) In terms of Spatial state of water environment, the water quality of Zhuzhao New River and Wanfu River is poor, and Dongyu River water quality is better. Zhuzhao New River and Wanfu River water qualityis often worse than grade $\mathrm{V}$ or V, and Dongyu River water quality is mostly maintained in the grade IV. Through the analysis on the spatial revolution characteristics of water quality and chemical oxygen demand(COD), as a result, water quality is poor in the northern region,and the water quality in the southern region is better in Heze. Although the water quality has changed in recent years, the overall pattern is relatively stable.
\end{abstract}

\section{Introduction}

The quality of water environment refers to the appropriate degree of the water environment on the survival and reproduction of the population and socioeconomic development, and usually refers to the degree of pollution in the water environment $[1,2]$. With the rapid development of the global economy and the growth of the population, the shortage of water resources has become a key problem that restricts the sustainable development of social and economic development in many countries and regions [3]. Over the past few decades, the change in globle climate and human activities have produced significant changes on the circulation of water resources. Therefore, it is important to research systemically the ecological and environmental protection of Heze city basin, and understand the sustainable development and utilization of water environment and the formation and evolution of water resources. It has important guidance on learning about the temporal and spatial characteristics of water cycle elements under the conditions of crowd activities and meteorological changes effect [4-6].

Through the study on the evolution of the water environmental quality in time and space, the root causes of the problem of water environment in Heze is explored. It can actively promot the construction of ecological civilization, and improve the water quality of the environment. Moreover, it is contirbute to find a suitable for the local economic and social development [7-10].

\section{Materials and methods}

\subsection{Study area}

Heze is situated between $34^{\circ} 33^{\prime} 33^{\prime \prime}-35^{\circ} 44^{\prime} 00^{\prime \prime} \mathrm{N}$ and $114^{\circ} 47^{\prime} 30^{\prime \prime}-16^{\circ} 24^{\prime} 15^{\prime \prime} \mathrm{E}$ along the southwest of Shandong Province, with the total area of 12239 $\mathrm{km} 2[11]$. It borders Henan Province to the south and the Jining City to the east. Heze is located in the West Lake system in the Yellow River and the Yellow River Old Course Triangle area due to the formation of the Yellow River burst alluvial plains. Most of the water near the east-west parallel migration and exit, remitted to Nansi Lake. In addition to the Yellow River, the inland rivers are mainly Dongyu River, Zhuzhao New River and Wanfu River (Figure 1).

\subsection{Research methods}

Chemical oxygen demand (COD), permanganate index, biochemical oxygen demand (BOD5) and ammonia nitrogen $(\mathrm{NH} 3-\mathrm{N})$ were selected among the evaluation indexes. The research method adopts the integrated pollution index method, and the method used in this

\footnotetext{
* Corresponding author: Qiang Zhao@zhaoqiang8827@sina.com
} 
evaluation is the relative quality of the parameters overlay type index method [12-14].

\subsection{Date sources}

From 2006 to 2014, Heze Municipal Environmental Monitoring Center Station routinely monitored 3 major rivers such as Zhao River, Dongyu River and Wanfu River. According to the condition of section monitoring, three sections are selected for each river respectively, and a total of nine monitoring sections are monitored (Figure 1).

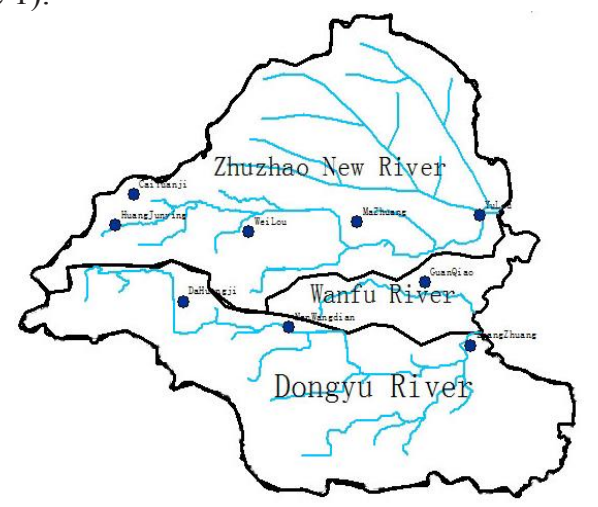

Fig. 1. Geographical distribution of monitoring points

\section{Results and discussion}

\subsection{Interannual Variability of Water Environmental Quality}

\subsubsection{Chemical oxygen demand (COD)}

The chemical oxygen demand of Zhuzhao New River is decreasing from 2006 to 2014 , and the maximum value is $45.6 \mathrm{mg} / \mathrm{L}$ in 2007. From 2008 to 2012, the annuai content of COD decreased obviously. The chemical oxygen demand of Dongyu River reached the maximum in 2008 and changed steadily from 2009 to 2014. The chemical oxygen demand of Wanfu River increased from 2014 to 2006. By 2012, the chemical oxygen demand changes more smoothly and all the values are below $30 \mathrm{mg}$ / L (Figure 2).

\subsubsection{Biochemical oxygen demand $\left(B O D_{5}\right)$}

As shown in Figure 2, the total oxygen demand of Zhuzhao New River decreased from 2006 to 2014 year by year, and rebounded in 2011 and 2014, but not higher than $11.52 \mathrm{mg} / \mathrm{L}$ in 2006. The content of Biochemical Oxygen Demand in Dongyu River fluctuated greatly from 2006 to 2010, with a relatively stable change from 2010 to 2014. The change of Biochemical Oxygen Demand of Wanfu River was relatively stable from 2006 to 2012. A significant decrease in 2013 and a sharp increase in 2014 with a content of $8.9 \mathrm{mg} / \mathrm{L}$.

\subsubsection{Ammonia nitrogen $\left(\mathrm{NH}_{3}-\mathrm{N}\right)$}

Analysis of Figure 3 shows: The content of ammonia nitrogen in Zhuzhao New River decreased obviously, and the change was more stable since 2009. The content of ammonia nitrogen in Dongyu River reaches its maximum in 2007 , which is $1.41 \mathrm{mg} / \mathrm{L}$, and the content of ammonia nitrogen is relatively stable since 2008. The ammonia nitrogen content of Wanfu River showed a downward trend as a whole, reaching the lowest value of $0.78 \mathrm{mg} / \mathrm{L}$ in 2009

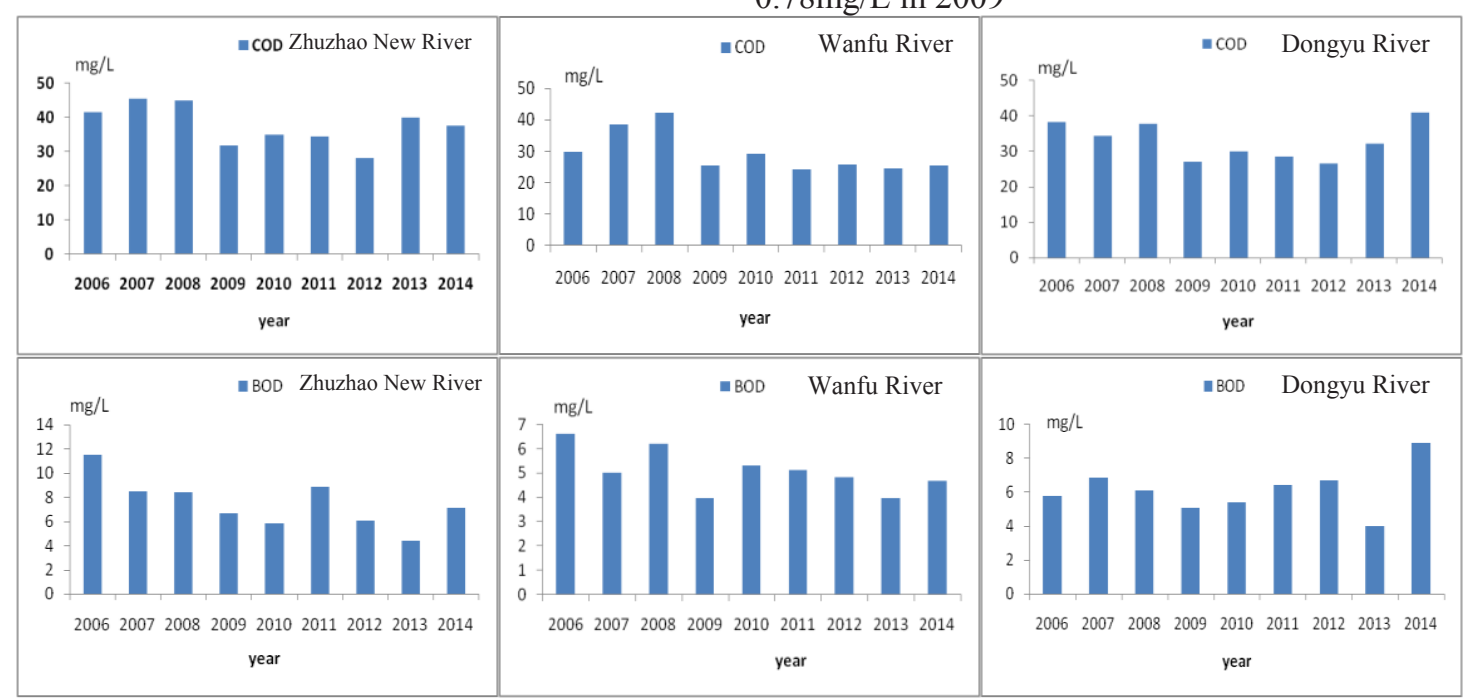

Fig. 2. Concentration of $\mathrm{COD}$ and $\mathrm{BOD}_{5}$ in Heze City 


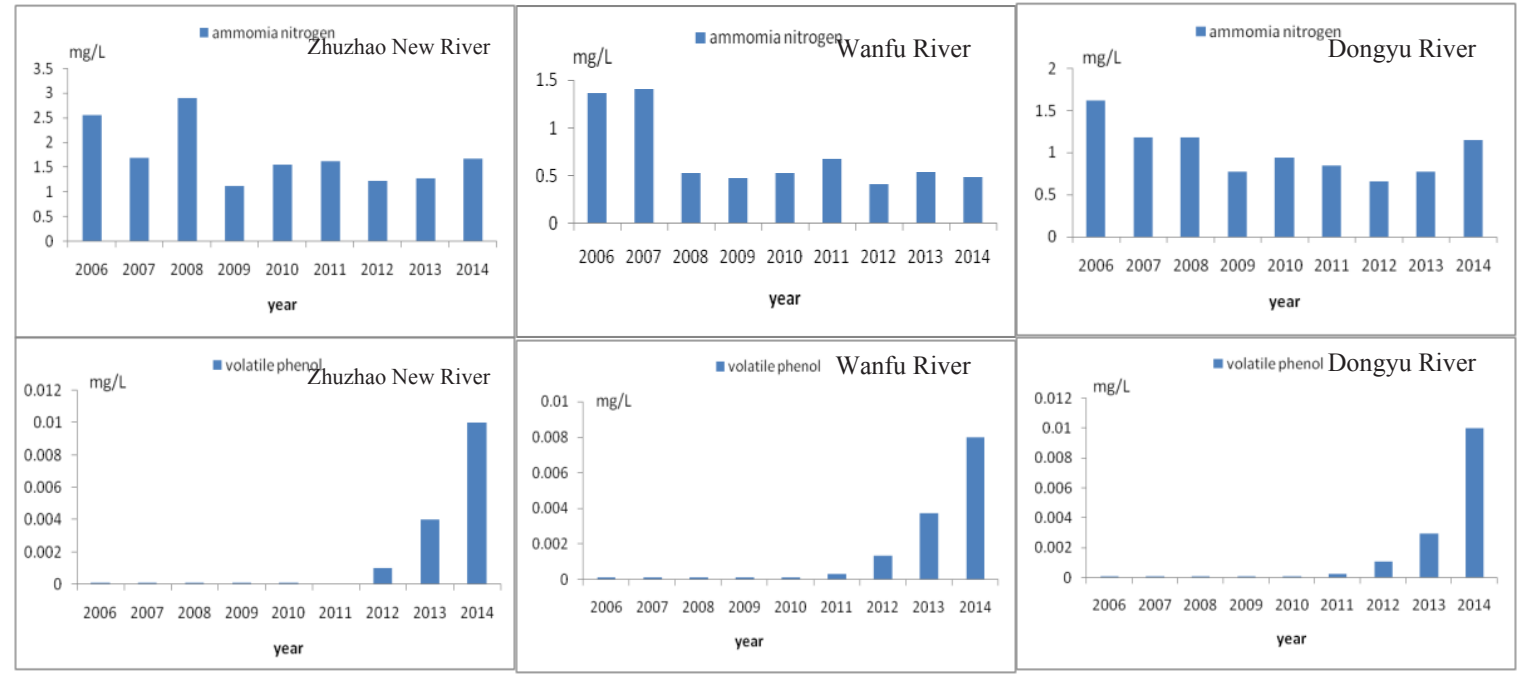

Fig. 3. Concentration of $\mathrm{NH}_{3}-\mathrm{N}$ and volatile phenol in Heze City

\subsubsection{Volatile phenol}

The content of volatile phenol in Zhuzhao New River maintained at $0.001 \mathrm{mg} / \mathrm{L}$ from 2006 to 2012, and an significant growth in 2012-2014; The volatile phenol content of Dongyu River has been changed steadily from 2006 to 2011, and it has been increased obviously since 2012. The volatile phenol content of Wanfu River was stable from 2006 to 2012. An obvious growth from 2012 to 2014 , reaching the maximum value of grade IV water quality (Figure 3).

\subsection{Interannual Variability of Water Environmental Quality}

\subsubsection{Chemical oxygen demand (COD)}

As shown in Figure 4, the chemical oxygen demand in space can be roughly divided into three stages. From 2006 to 2011, the chemical oxygen demand of Zhuzhao New River and Wanfu River are larger, and they are the major pollution centers. In 2012, the water environment pollution center shifted downward, with Wanfu River and Dongyu River as the main pollution centers. By 2014, the chemical oxygen demand of three rivers in Heze has risen again. In this year, the comprehensive index of water environment pollution has also risen sharply. The pollution center has also been transferred to the upper reaches of Zhao Xin River and Wanfu River.

\subsubsection{Biochemical oxygen demand $\left(B O D_{5}\right)$}

In 2006-2008, Zhuzhao New River had a higher biochemical oxygen demand and was the main pollution center. In 2010, the biochemical oxygen demand of the three rivers gradually approached and the pollution center began to change. From 2011 to 2014, the contents of the Zhuzhao New River and Wanfu River catchments have been increasing year by year.

\subsubsection{Ammonia nitrogen $\left(\mathrm{NH}_{3}-\mathrm{N}\right)$}

Ammonia nitrogen is mainly concentrated in the Zhuzhao New River Basin, and Wanfu River in the Dongyu River Branch of the river due to the river branch of the pollutants. So its ammonia nitrogen content is relatively high. The Dongyu River fish ammonia content decreased, the overall pollution of the river also gradually weakened.

\subsubsection{Volatile phenol}

From 2006 to 2010, the volatile phenol contents of three rivers in Heze City were lower than $0.0001 \mathrm{mg} / \mathrm{L}$. Beginning in 2011, the volatile phenol content in rivers increased mainly in the Zhuzhao New River basin. In 2012 and 2013, the content of three rivers increased; in 2014 , the content of three rivers increased greatly.

\subsubsection{Water quality status}

The water quality of three rivers in Heze improved from 2006 to 2014. The water quality of Dongyu River is in a good condition. Most of the water quality in the past nine years has remained at the level IV. Zhuzhao New River and Wanfu River water quality is poor, and most of the river pollution centers in Zhuzhao New River and Wanfu River nearby. The spatial evolution of water quality is consistent with the spatial evolution of the application of COD. 


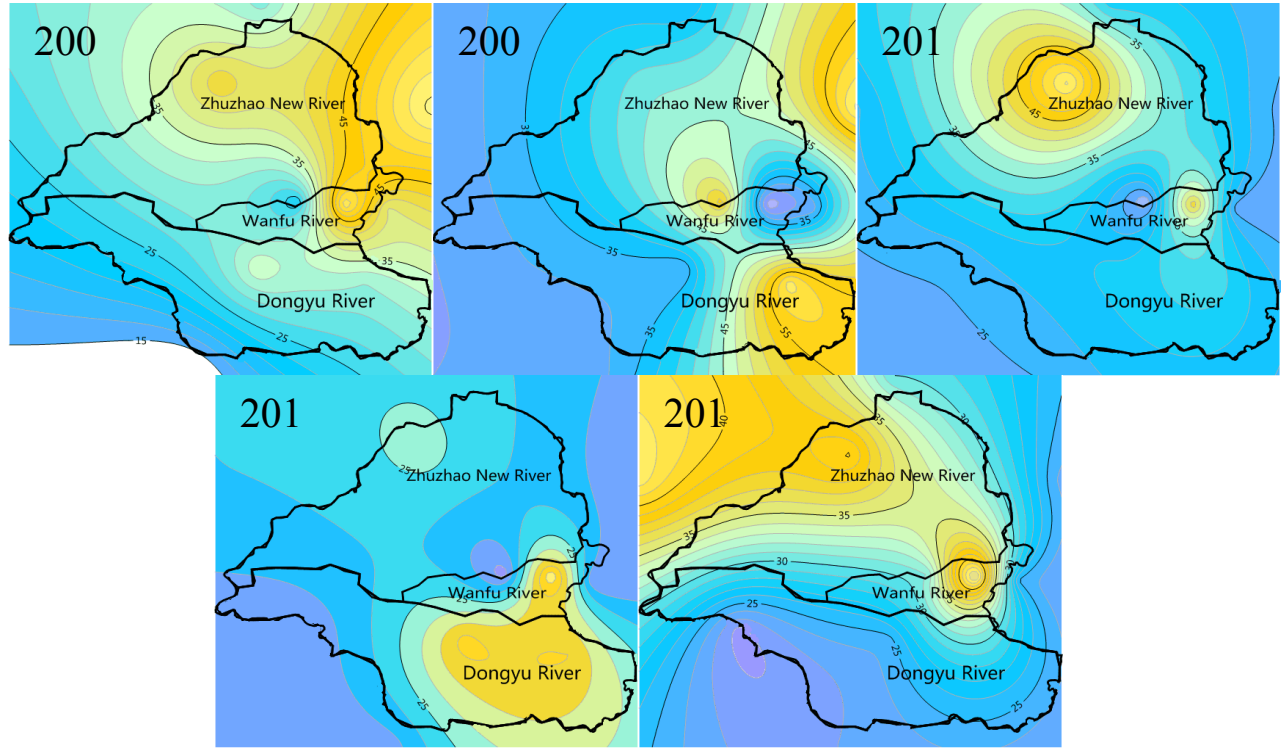

Fig. 4.Spatial evolution process of chemical oxygen demand from 2006 to2014
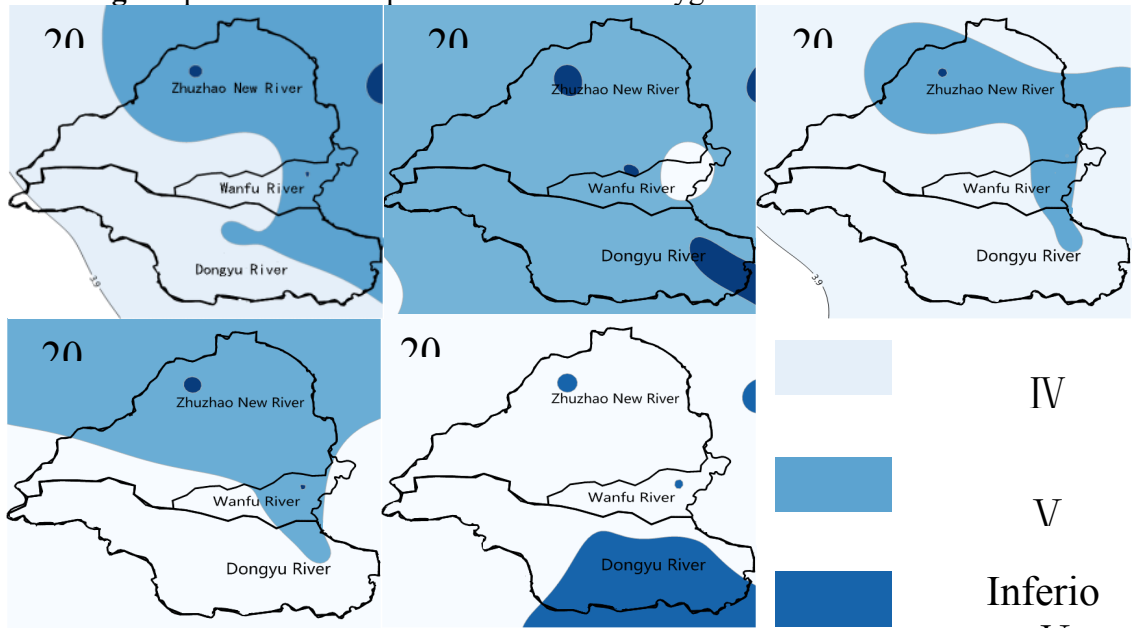

IV

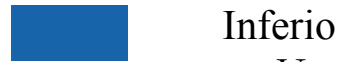

Fig. 5. Spatial evolution of river water quality during 2006 - 2014

\subsection{Spatial and temporal change characteristics summary}

By analyzing the temporal and spatial changes of the water environment of the three rivers in Heze City, such as the Suzhao River, the Dongyu River and the Wanfu River, the interannual variation characteristics of the water environment of the three rivers in Heze City are obtained. Zhuzhao New River comprehensive index of river pollution is the largest of the three rivers, the change is also greater. The pollution index of Dongyu River is relatively small, and the change range is relatively stable. From 2006 to 2013, the water quality of three rivers in Heze has gradually improved, and the water quality has been aggravated by 2014 . Among the three rivers, the Dongyu River has better water quality. The pollution center is mainly in the lower reaches, and the water quality is dominated by grade IV and V. The water quality of Wabfu River was second. Due to the small drainage area in Heze City, the water quality is dominated by Grade V and Grade IV. Zhuzhao New River Pollution Center is mainly concentrated in the downstream often appear V category or Inferior V class water [15].

\section{Conclusion}

By monitoring water quality of monitoring sections of Zhuzhao New River, Wanfu River and Dongyu River in Heze City, The spatial and temporal evolution of water environment in Heze City over the past 9 years has been systematically studied and analyzed. The results show that from 2006 to 2014 overall water quality is gradually improving in Heze City. Among them, the quality of water environment has been improved year by year from 2006 to 2013, and indicators of water pollution in rivers decreased year by year. By 2014, the quality of water environment will decrease and the concentration of pollutant index substances in rivers will rise to a certain extent. Among the three rivers, the water quality of Zhuzhao New River in is worse, followed by Wanfu River, and the water quality of Dongyu River is the best. Based on the spatial evolution of water quality and the evolution of pollutants, as a result, the water quality in the northern part of Heze City is poor and the water quality in the southern part is better. 


\section{Acknowledgements}

This study was financially supported by the Natural

Science Foundation of China (NO.41471160)

\section{References}

1. J Cai, O Varis, H Yin, J. Clean. Prod. 142, 4:29012910 (2016)

2. S Y Korkanç, S Kayıkçı, M Korkanç, J. Afr. Earth. Sci. 129:481-491 (2017)

3. G Cao, D Han, J Moser, Environ. Manage. 51, 6:1109-1125 (2013)

4. Q Zhou, W Wang, Y Pang, Z Zhou, H Luo, Water Science and Engineering, 8, 4:263-272 (2015)

5. China Environmental Yearbook Environmental Monitoring Branch editorial board, The China Environmental Yearbook 2005 (The China Environmental Yearbook, 2005) (in Chinese)

6. S K Barik, P R Muduli, B Mohanty, A T Behera, S Mallick, Cont. Shelf. Res. 136:39-56 (2017)

7. W Luo, $\mathrm{H} \mathrm{Li}, \mathrm{H} \mathrm{Mu}$, Water environment protection (China Water Conservancy and Hydropower Press, 2009) (in Chinese)

8. S Su, D Li, Q Zhang, R Xiao, F Huang, Water. Res. 45, 4:1781-1795 (2011)

9. W Sun, C Xia, M Xu, J Guo, G Sun, Ecol. Indic. 66:306-312 (2016)

10. L Ren, E Cui, H Sun, Environ. Sci. Pollut, Res. Int. 21, 23:13646-13655 (2014)

11. Z Zhang. Shandong Geography (Beijing Normal University Press, 2014) (in Chinese)

12. L Tong, Heilongjiang science and technology information, 15:113-113 (2016) (in Chinese)

13. G Xu, Z Jing, Journal of Tianjin University, 50, 7:710-716 (2017)

14. T Sun, M Zhang, M Li, X Wang, Environmental Science and Technology, v. 37, 4:185-190 (2014) (in Chinese)

15. N C Ujjania, M Dubey, Curr. Science. 108, 8:14301433 (2015) 